\title{
BMJ Open Correlates of former smoking in patients with cerebrovascular disease: a cross-sectional study
}

\author{
Rojiemiahd K Edjoc, ${ }^{1}$ Robert D Reid, ${ }^{1}$ Mukul Sharma, ${ }^{2}$ Louise Balfour, ${ }^{3}$ \\ Michael Procino ${ }^{3}$
}

To cite: Edjoc RK, Reid RD, Sharma M, et al. Correlates of former smoking in patients with cerebrovascular disease: a cross-sectional study. BMJ Open 2015;5:e005753. doi:10.1136/bmjopen-2014005753

- Prepublication history for this paper is available online. To view these files please visit the journal online (http://dx.doi.org/10.1136/ bmjopen-2014-005753).

Received 23 May 2014 Revised 19 December 2014 Accepted 22 December 2014

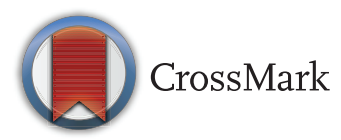

\footnotetext{
${ }^{1}$ Division of Prevention and Rehabilitation, University of Ottawa Heart Institute, Ottawa, Canada

${ }^{2}$ McMaster University, Population Health Research Institute, Hamilton, Ontario, Canada

${ }^{3}$ University of Ottawa, Ottawa, Ontario, Canada
}

Correspondence to Dr Rojiemiahd K Edjoc; redjoc@hotmail.com

\section{ABSTRACT}

Objective: To identify multilevel correlates of former smoking in patients with cerebrovascular disease.

Design: Secondary data analysis of the Canadian Community Health Survey.

Methods: We used data from the 2007-2008

Canadian Community Health Survey (CCHS). Smoking status (former smoking vs smoker) was described by multilevel correlates of former smoking. A multilevel approach for variable selection for this study was used to understand how multiple levels in society can have an impact on former smoking. The study sample was selected from those respondents of the CCHS that reported they suffered from stroke symptoms. Logistic regression was used to predict former smoking in patients with cerebrovascular disease while controlling for multilevel confounders. Proportions were weighted to reflect the Canadian population.

Results: There were 172355 respondents who reported to suffer from stroke. From this sample, $36.5 \%$ were smokers and $63.5 \%$ were former smokers. Age groups 55-69 and 70-80 and higher education (secondary education +) were positively related to former smoking. Household and vehicle smoking restrictions significantly predicted former smoking. Counselling advice from a physician and having access to a general practitioner were correlates of former smoking. Finally, the use of buproprion was positively related to former smoking.

Conclusions: There are multilevel correlates of former smoking in smokers with reported stroke symptoms. These correlates include older age groups, higher education, household and vehicle smoking restrictions, pharmacotherapy use (bupropion), access to a general practitioner and counselling advice from a physician.

\section{INTRODUCTION}

Smoking is an independent risk factor for incident and recurring stroke. ${ }^{1-3}$ It has been found that smoking cessation can reduce the relative risk of stroke and transient ischaemic attack (TIA) by $50 \%{ }^{4}$ and stroke-related hospitalisations. ${ }^{5}$ Despite the supporting evidence regarding the benefits of smoking cessation for smokers with cerebrovascular disease, there is evidence that $89 \%$ of these

\section{Strengths and limitations of this study}

- This study is the first to elucidate correlates of former smoking in this population at a multilevel.

- The size of the study provides adequate power for the statistical analyses.

- The cross-sectional nature of the study and selfreported outcomes such as smoking status and the presence of stroke symptoms may result in social desirability bias.

smokers were still smoking 12 months after their event. ${ }^{6}$

Stroke prevention guidelines recommend that healthcare providers strongly advise every smoker who is at high risk for a stroke or TIA to quit, and provide specific assistance with quitting, including counselling and pharmacotherapy. ${ }^{3} 7$

There are very few published smoking cessation intervention (SCI) studies in stroke and patients with TIA. A recent systematic review found a non-significant effect of SCI's on quitting in stroke and patients with TIA. ${ }^{8}$ The authors found that with the available studies, there was a suboptimal use of evidence-based approaches to smoking cessation comprised of counselling, pharmacotherapy and follow-up. ${ }^{8}$

More interventions need to be developed by identifying significant correlates of former smoking among these high-risk smokers. The socioecological model proposed by Sorensen and associates ${ }^{9}$ explicate factors that influence different groups to use or not use tobacco (figure 1). These factors include population characteristics and socioeconomic status (SES), individual, interpersonal, community and organisational factors. Based on this socioecological model, the present study elucidated multilevel correlates of former smoking using data from the Canadian Community Health Survey (CCHS). There has not been any study that 


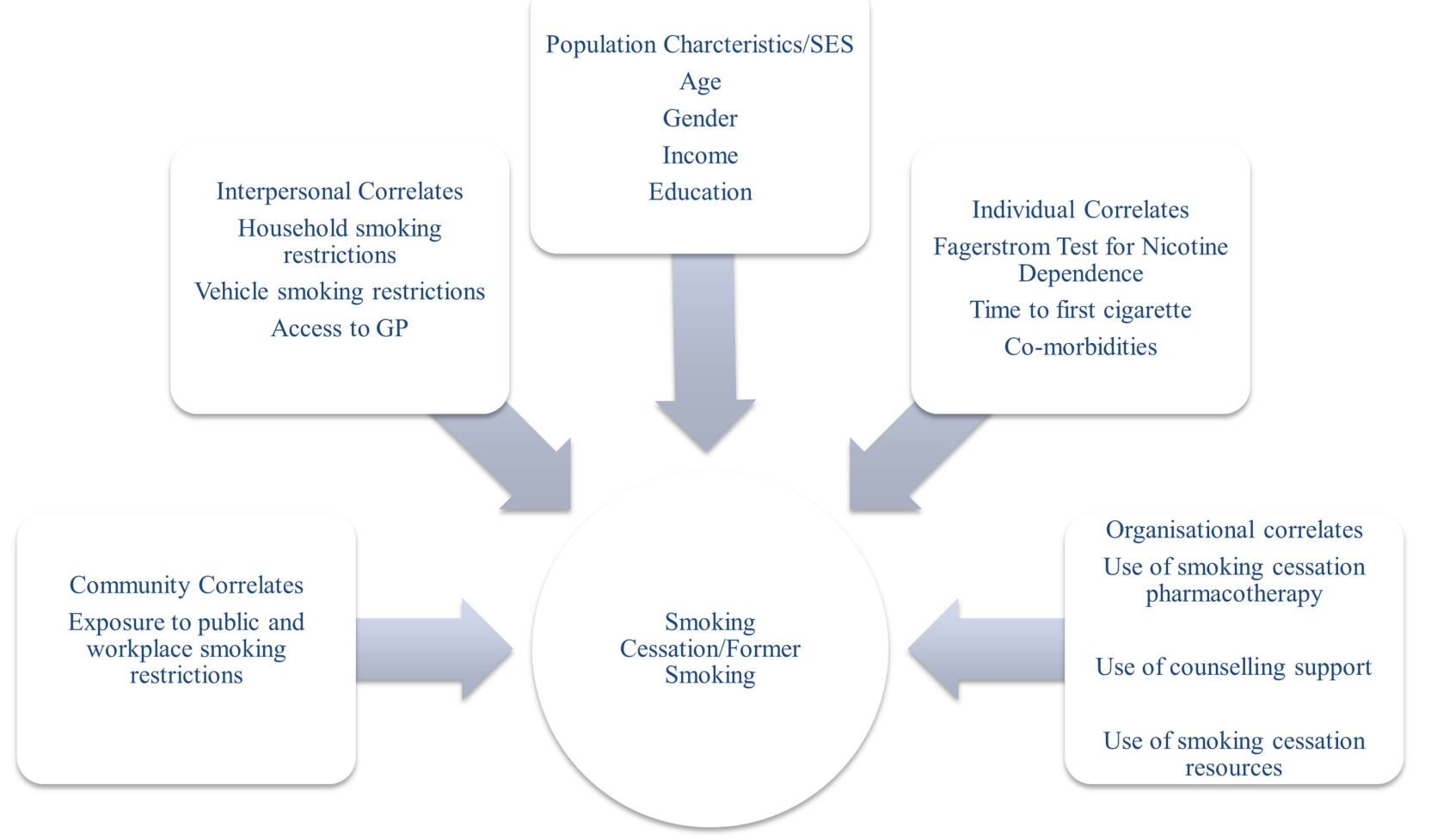

Figure 1 Socioecological model for multilevel correlates of former smoking in respondents with cerebrovascular disease.

has systematically explored the impact of multilevel correlates on the cessation attempt and thus is the impetus for the present study.

\section{METHODS}

Data from the 2007-2008 CCHS were used for the present study. The CCHS is a cross-sectional survey that collects information related to the factors that contribute to health, social and economic determinants of Canadians. ${ }^{10}$ The CCHS utilises a complex sampling strategy with stratification and multiple stages of selection yielding a sample that is representative of $98 \%$ of the Canadian population. ${ }^{10}$

Only individuals who reported the effects of stroke were included in the present analysis. Stroke symptoms were defined as those who reported were experiencing stroke symptoms due to a recent stroke or TIA within the past year. No further information was available. From this sample, smoking status (smoking vs former smoking) was selected as the dependent variable. Important correlates were grouped by population characteristics and SES, individual, interpersonal, community and organisational level. Population characteristics included: sex and age. Age was re-coded into four categories (ages 12-34; 35-54; 55-69 and 70-80+). SES included: income and education. Individual level correlates included: comorbidities such as depression, diabetes mellitus, hypertension and alcohol consumption. Interpersonal level correlates included: having household and vehicle smoking restrictions and access to a general practitioner (GP). Community level correlates included: exposure to public and workplace smoking restrictions. Organisational level correlates were defined as the use of smoking cessation resources such as pharmacotherapy (nicotine replacement therapy (NRT) and bupropion) and counselling support provided by a physician or referral to a smoking cessation group. Ideally, varenicline would be included in the list of pharmacotherapy. Unfortunately, at the time of this survey, varenicline was not yet approved for use in Canada and was not collected by the CCHS. Owing to the complex survey design of the CCHS, adjusted weight was calculated for each respondent taking into account national average design effects and the relative sampling weights.

\section{Statistical analysis}

All statistical analyses were performed using Statistical Analysis Software (SAS) using SURVEYFREQ and SURVEYLOGISTIC procedures.

Descriptive analyses were performed to describe smoking status (smoker and former smoker) and correlates of interests in respondents who reported to have stroke symptoms. A $\chi^{2}$ test of significance was used to determine significant differences between crosstabulated proportions. Significance was reported at $95 \%$ confidence or having a value of $\mathrm{p}<0.05$.

Logistic regression was used to predict the dependent variable of reported former smoking while controlling for each identified correlate. Significant correlates of former smoking were expressed by OR point estimates at a $95 \%$ confidence level (CI). The method of model 
building for logistic regression analyses was forwardstepwise selection. The Wald statistic was used for variable selection. Independent variables were identified as significant correlates if the $\mathrm{p}$ value was less than 0.05 $(\mathrm{p}<0.05)$.

\section{RESULTS}

The overall weighted sample was 172355 individuals who reported to suffer from stroke symptoms. From this sample $36.5 \%$ reported to be smokers and $63.5 \%$ reported to be former smokers.

There were more males who reported they were former smokers than females $(p<0.0001)$. In the smoking cohort, more males were smokers than females $(p<0.0001)$. Individuals who were former smokers were older than smoking individuals. In general, this cohort had less than secondary education and were earning an annual income of \$20 000-39000.

Individuals who were former smokers reported to have higher proportions of household $(\mathrm{p}<0.0001)$ and vehicle smoking restrictions $(p<0.0001)$ compared to smoking individuals. Exposure to public smoking restrictions $(\mathrm{p}<0.0001)$ was higher in smokers compared to former smokers.

Respondents who were former smokers compared to current smokers reported they used NRT $(p<0.0001)$ more frequently as well as bupropion $(p<0.0001)$. Smokers reported more physician counselling $(\mathrm{p}<0.0001)$ than former smokers. Smoking individuals reported higher proportions of alcohol consumption ( $>2$ drinks per day; $\mathrm{p}=0.03)$, depression $(\mathrm{p}<0.0001)$ and diabetes $(\mathrm{p}=0.21)$ than former smokers.

Female sex and comorbidities such as alcohol consumption and depression reduced the likelihood of former smoking. Age groups 55-69 and 70-80 years old were significant correlates of former smoking.
Household and vehicle smoking restrictions significantly predicted former smoking while exposure to workplace and public place smoking restrictions did not. The use of pharmacotherapy such as bupropion significantly predicted former smoking while the use of NRT did not. Counselling advice from a physician and having a GP were correlates of former smoking (tables 1-3).

\section{DISCUSSION}

The aim of this study was to identify the correlates of former smoking in smokers with reported stroke symptoms at multilevels. Income and older age were predictive of former smoking while higher education predicted former smoking in this cohort. These results are in line with previous investigations of gender effects, ${ }^{11-13}$ older $\operatorname{age}^{11} 12$ and level of income ${ }^{11} 1214$ vis a vis smoking and cessation. Our results indicate there are fewer women who are former smokers than men. Reynaso et $\mathrm{al}^{13}$ outline that there may be several working hypotheses that may explain this result. First, women may respond poorly to NRT. Second, women are more vulnerable to depression and anxiety symptomatology following cessation. Third, there may be concerns regarding postcessation weight gain and body-shape concerns for women compared to men. Fourth, women's menstrual cycle effects enhance nicotine withdrawal symptoms following cessation. Fifth, women do not receive or do not respond to the beneficial effects of social support during cessation. ${ }^{13}$ They suggest that a varied approach to smoking cessation be taken in light of these hypotheses. For example it is imperative to consider an approach with lengthier treatments for women following NRT termination. $^{13}$ Health professionals should also consider adjunct programmes during the cessation attempt for women who have concerns about weight gain. ${ }^{13}$ There should be concurrent treatment

\begin{tabular}{|c|c|c|c|}
\hline Covariates & Smoker (\%; n=62 960) & Former smoker (\%; n=109 395) & p Values \\
\hline Males & 56.4 & 62.9 & $<0.0001$ \\
\hline Females & 43.6 & 37.1 & $<0.0001$ \\
\hline Age & & & $<0.001$ \\
\hline $12-34$ & 4.2 & 1.5 & \\
\hline $35-54$ & 20.4 & 3.1 & \\
\hline $55-69$ & 38.2 & 24.4 & \\
\hline $70-80+$ & 31 & 46.1 & \\
\hline Education & & & $<0.001$ \\
\hline$<$ Secondary & 18.9 & 18.2 & \\
\hline Secondary & 11.5 & 13.6 & \\
\hline Some postsecondary & 3.8 & 5.1 & \\
\hline Income & & & $<0.001$ \\
\hline None or $<\$ 20000$ & 20.7 & 14.3 & \\
\hline$\$ 20000-\$ 39000$ & 25.3 & 29.3 & \\
\hline$\$ 40000-\$ 59000$ & 19.1 & 17.3 & \\
\hline$\$ 60000-\$ 79000$ & 6.2 & 7.11 & \\
\hline$\$ 80000+$ & 10.5 & 13.5 & \\
\hline
\end{tabular}


Table 2 Study cohort characteristics

\begin{tabular}{|c|c|c|c|}
\hline Covariates & Smoker (\%) (n=62 960) & Former smoker (\%) (n=109 395) & p Values \\
\hline \multicolumn{4}{|l|}{ Smoking restrictions } \\
\hline Household & 35.5 & 74.0 & $<0.0001$ \\
\hline Workplace & 29.8 & 10.5 & 0.004 \\
\hline Vehicle & 0.0 & 93.7 & $<0.0001$ \\
\hline Public & 0.0 & 93.3 & $<0.0001$ \\
\hline Have access to GP & 86.7 & 94.9 & $<0.0001$ \\
\hline Smoking cessation aids & 0.0 & 0.0 & - \\
\hline Nicotine replacement therapy (NRT) gum & 0.0 & 0.1 & $<0.0001$ \\
\hline NRT patch & 0.0 & 0.4 & $<0.0001$ \\
\hline Zyban/bupropion & 4.5 & 0.5 & $<0.0001$ \\
\hline MD counselling & 0.5 & 0.0 & $<0.0001$ \\
\hline One-to-one referral & 0.0 & 0.0 & - \\
\hline \multicolumn{4}{|l|}{ Referral to smoking cessation group } \\
\hline Alcohol drinking (>2 drinks/day) & 49.1 & 7.9 & 0.03 \\
\hline Depression & 41.7 & 35.6 & $<0.0001$ \\
\hline Diabetes & 20.7 & 8.9 & 0.21 \\
\hline Hypertension & 7.9 & 20.4 & 0.02 \\
\hline
\end{tabular}

Table 3 Correlates of smoking cessation of study cohort

\begin{tabular}{|c|c|c|c|}
\hline & OR & $\begin{array}{l}\text { Lower } \\
95 \% \mathrm{Cl}\end{array}$ & $\begin{array}{l}\text { Upper } \\
95 \% \mathrm{CI}\end{array}$ \\
\hline \multicolumn{4}{|l|}{ Population characteristics } \\
\hline Female sex & 0.41 & 0.41 & 0.42 \\
\hline Age 12-34 & 0.01 & 0.001 & 0.01 \\
\hline Age $35-54$ & 0.03 & 0.02 & 0.03 \\
\hline Age 55-69 & 1.20 & 1.1 & 1.19 \\
\hline Age $70-80$ & 1.50 & 1.61 & 1.67 \\
\hline \multicolumn{4}{|l|}{ Socioeconomic status } \\
\hline Less than secondary & 0.90 & 0.88 & 0.93 \\
\hline Secondary education & 1.25 & 1.22 & 1.29 \\
\hline $\begin{array}{l}\text { Some postsecondary } \\
\text { education }\end{array}$ & 1.24 & 1.23 & 1.24 \\
\hline Postsecondary & 1.12 & 1.1 & 1.15 \\
\hline $\begin{array}{l}\text { No income or less } \\
\$ 20000\end{array}$ & 1.48 & 1.45 & 1.52 \\
\hline$\$ 20000-\$ 39000$ & 1.30 & 1.24 & 1.29 \\
\hline$\$ 40000-\$ 59000$ & 1.10 & 1.06 & 1.11 \\
\hline$\$ 60000-\$ 79000$ & 0.65 & 0.63 & 0.67 \\
\hline$\$ 80000+$ & 0.7 & 0.67 & 0.7 \\
\hline \multicolumn{4}{|l|}{ Individual level } \\
\hline $\begin{array}{l}\text { Alcohol consumption } \\
\text { (>2 drinks/day) }\end{array}$ & 0.70 & 0.70 & 0.71 \\
\hline Depression & 0.90 & 0.88 & 0.91 \\
\hline Hypertension & 1.21 & 1.18 & 1.24 \\
\hline Diabetes & 1.4 & 1.34 & 1.38 \\
\hline \multicolumn{4}{|l|}{ Interpersonal level } \\
\hline $\begin{array}{l}\text { Household smoking } \\
\text { restrictions }\end{array}$ & 1.10 & 1.05 & 1.08 \\
\hline $\begin{array}{l}\text { Vehicle smoking } \\
\text { restrictions }\end{array}$ & 2.98 & 2.91 & 3.06 \\
\hline Access to a GP & 1.30 & 1.23 & 1.3 \\
\hline \multicolumn{4}{|l|}{ Organisational level } \\
\hline Zyban/bupropion & 15.52 & 14.03 & 17.16 \\
\hline MD counselling & 1.52 & 1.39 & 1.67 \\
\hline
\end{tabular}

programmes for women who have a history of anxiety/ depression. ${ }^{13}$ Finally, the timing of smoking cessation interventions early in the follicular phase of the menstrual cycle should be considered. ${ }^{13}$

In regards to income, there seems to be an inverse effect of those who are at the lower levels of SES and former smoking. A recent review by Hiscock $e t \mathrm{al}^{14}$ suggested that the higher smoking prevalence in lower SES groups and lower smoking cessation rates might be a result of the clustering of disadvantages. These disadvantages include: a reduced social support for quitting, low motivation to quit, increased addiction to tobacco, increased likelihood of not completing courses of pharmacotherapy or behavioural support sessions, psychological differences such as lack of self-efficacy, and susceptibility tobacco industry marketing. ${ }^{14}$ As a result, quit attempts in this population are significantly less likely to be successful. ${ }^{14}$

Koning et $a l^{15}$ found that each additional year of education reduced the risk of continued smoking. ${ }^{15}$ Their data suggested that people with higher education may be able to better understand the consequences of longterm smoking and may have more resources available for them to quit smoking.

Our findings suggest that comorbid conditions such as alcohol consumption and depression significantly decreased the likelihood of former smoking. These findings are supported by evidence suggesting that cerebrovascular patients experience higher rates of comorbidity particularly depression. ${ }^{16-18}$ Compared to cardiac patients, patients with a recent stroke suffered a three to fivefold increased risk of depressive disorders ${ }^{16}$ as well as higher proportions of alcohol consumption and hypertension. ${ }^{19}$

These findings may have clinical implications particularly for this population, as comorbid conditions such as depression and increased alcohol consumption are 
significantly more common in patients who smoke. Considering their association with increased smoking behaviour, comorbidities may be hindering the success of quitting smoking. The hindering effect of comorbidity on former smoking is especially problematic as smoking increases blood coagulability, platelet aggregation, thrombus formation and endothelial damage, ${ }^{20}$ thus increasing the chance of a stroke twofold ${ }^{21}$ and of stroke recurrence. ${ }^{21} 22$ Quitting smoking has been shown to reduce the risk of stroke to that of a nonsmoker after 5 years ${ }^{23}$ and reduce the risk HR of stroke recurrence from 1.71 to $1.39(\mathrm{p}<0.05) .{ }^{24}$ It is imperative that smoking cessation be incorporated in secondary prevention practice while taking these significant comorbidities into account. Depression and excessive alcohol consumption might impede cessation in people with cerebrovascular disease. However due to the limitation of cross-sectional studies, we do not know if these comorbidities existed before or after the reported stroke. Further study regarding the effects of these comorbidities on cessation using other study designs might be warranted.

Population-based interventions such as household, workplace, vehicle and public smoking restrictions have all been found to predict smoking abstinence. ${ }^{25-27}$ They have also been found to reduce cigarette consumption, and initiation and increase smoking cessation rates. ${ }^{25-27}$ These authors suggest that population-based interventions are antitobacco socialisation tools that may promote the internalisation of behavioural norms against the initiation or continuation of smoking. Our results are partially in line with this evidence. We found that household and vehicle smoking restrictions predicted smoking cessation but not so with workplace or public smoking restrictions. It is not known why workplace and public smoking restrictions did not predict smoking cessation especially since their implementation under the Smoke Free Ontario Act $(\mathrm{SFOA})^{28-30}$ in Ontario and similar legislations across Canada. Since their implementation, smoking prevalence in Canada has been dramatically decreased. Perhaps the insignificant effect of public and workplace smoking restrictions may be explained in the decrease of funding in the SFOA in 2007-2008 of 60 million, down 2.5 million from the year before of 62.5 million in 2006-2007.31 32 Similar reductions in tobacco control funding can be observed in other provinces. ${ }^{29}{ }^{30}$ There is a documented association between population interventions effectiveness and sustained funding. ${ }^{33}$

A similar situation was observed with the California Model in the state of California. The California Model is similar to the SFOA and is a population intervention that used workplace and public place smoking restrictions to de-normalise tobacco use. ${ }^{33}$ Pierce $e t a l^{33}$ found that the initial effect of the California Model to decrease smoking prevalence in the state dissipated as their funding was reduced.

In light of this conundrum, there is evidence that suggests that household and vehicle-smoking restrictions are more effective because they are less regulated. ${ }^{34} 35$ These authors suggest that smoking restrictions such as at home or in a vehicle are effective because those who implement them do so by choice and not through forced legislation $^{33-35}$ thereby increasing the odds of smoking cessation.

We found that the use of pharmacotherapy such as bupropion and physician counselling increased the odds of former smoking but NRT use did not. According to Fiore et $a \hat{l}^{36}$, pharmacotherapy along with counselling and follow-up increases the odds of smoking cessation. NRT and bupropion have each been found to be more efficacious than placebo for increasing the odds of smoking cessation. ${ }^{37}$

The lack of effect of NRT may be indicative of the well-documented practice gap in healthcare in regards to smoking cessation. Young and Ward ${ }^{38}$ found that only $32 \%$ of physicians provided written materials for their patients and only $28 \%$ of physicians set a 'quit date' with their patients. Likewise Shaohua $e t a l^{39}$ found that many family physicians feel lack of time was their biggest barrier in terms of implementing smoking cessation practices. Their study found that less than half were willing or able to assist their patients to quit with the use of counselling, pharmacotherapy or arrange a follow-up visit to reinforce the benefits of smoking cessation. ${ }^{38}$ This is consistent with the stroke population as documented by Mouradian et al. ${ }^{6}$ Perhaps another explanation may be the lack of information regarding the effectiveness of smoking cessation medications and similar interventions in stroke and patients with TIA. Furthermore, physicians may be reluctant to prescribe NRT's due to their availability over the counter. Further research is required to determine if the latter explanations are supported by evidence.

Cross-sectional surveys such as the CCHS are useful for initial exploratory studies. They are far reaching and reflect 'a snapshot' of the population. However, there are limitations to our study and they will be explored here. Since both exposure and outcome were measured at the same time, one cannot be certain which is the exposure or the outcome. In other words, the rules for contributory cause cannot be fulfilled. For example, it is possible that respondents stopped smoking years before their stroke diagnosis. Owing to the nature of the crosssectional design of the CCHS, there is no way to ascertain which of the two (former smoking vs stroke diagnosis) came first. Unfortunately there is no available variable that quantifies the time-point of cessation in relation to respondents' stroke diagnosis. Another limitation would be the results that found sex and age as significant correlates of former smoking. Unfortunately, these are unmodifiable correlates. Future interventions should take into account modifiable correlates such as the implementation of household and vehicle smoking restrictions and the availability of pharmacotherapy and counselling support. Another limitation is the mode of collection of the data. Social desirability and recall bias for example could play an important role and a source 
of biases within this study. ${ }^{40}$ For example, since smoking status, the presence of stroke symptoms and comorbidities such as depression were self-reported, special care should be taken when interpreting our results. An example of social desirability effect would be respondents not accurately reporting their smoking status. Since smoking would be an undesirable image for some depending on age, gender or SES, data obtained might not be representative of the real picture found in the population. Ideally all smoking-related measures should be validated biochemically with breath samples measuring carbon monoxide levels or coitinine levels measuring the amount of nicotine in the blood. Furthermore, without an expert assessment from a healthcare professional of stroke symptoms or depression would also limit the generalisability of the results.

\section{CONCLUSION}

We found significant correlates of former smoking at multiple levels in smokers with reported stroke symptoms. Age and education level were significant correlates of former smoking as well as household and vehicle smoking restrictions and access to a GP. Finally, the use of bupropion along with physician counselling predicted former smoking.

Contributors RKE, RDR and MS made substantial contributions to conception and design, acquisition of data or analysis and interpretation of data. LB and MP assisted in revising the manuscript critically for important intellectual content. All authors provided approval of the version to be published.

Funding This research received no specific grant from any funding agency in the public, commercial or not-for-profit sectors.

\section{Competing interests None.}

Provenance and peer review Not commissioned; externally peer reviewed.

Data sharing statement No additional data are available.

Open Access This is an Open Access article distributed in accordance with the Creative Commons Attribution Non Commercial (CC BY-NC 4.0) license, which permits others to distribute, remix, adapt, build upon this work noncommercially, and license their derivative works on different terms, provided the original work is properly cited and the use is non-commercial. See: http:// creativecommons.org/licenses/by-nc/4.0/

\section{REFERENCES}

1. Shinton R, Beevers G. Meta-analysis of relation between cigarette smoking and stroke. BMJ 1989;298:789-94.

2. Hata J, Doi Y, Ninomiya $T$, et al. Combined effects of smoking and hypercholesterolemia on the risk of stroke and coronary heart disease in Japanese: the Hisayama study. Cerebrovasc Dis 2011;31:477-84.

3. Kern R, Nagayama M, Toyoda K, et al. Comparison of the European and Japanese guidelines for the management of ischemic stroke. Cerebrovasc Dis 2013;35:402-18.

4. Wannamethee SG, Shaper AG, Whincup PH, et al. Smoking cessation and the risk of stroke in middle-aged men. JAMA 1995;274:155-60.

5. Naidoo B, Stevens W, McPherson K. Modelling the short term consequences of smoking cessation in England on the hospitalisation rates for acute myocardial infarction and stroke. Tob Control 2000;9:397-400.

6. Mouradian MS, Majumdar SR, Senthilselvan A, et al. How well are hypertension, hyperlipidemia, diabetes, and smoking managed after a stroke or transient ischemic attack? Stroke 2002;6:1656-9.

7. Furie KL, Kasner SE, Adams RJ, et al. Guidelines for the prevention of stroke in patients with stroke or transient ischemic attack: a guideline for healthcare professionals from the American Heart Association/American Stroke Association. Stroke 2011;42:227-76.

8. Edjoc RK, Reid RD, Sharma M. The effectiveness of smoking cessation interventions in smokers with cerebrovascular disease: a systematic review. BMJ Open 2012;2:e002022. doi:10.1136/ bmjopen-2012-002022

9. Sorensen G, Barbeau E, Hunt MK, et al. Reducing social disparities in tobacco use: a social-contextual model for reducing tobacco use among blue-collar workers. Am J Public Health 2004;94:230-9.

10. Statistics Canada. The Canadian Community Health Survey (CCHS) 2007-2008. Statistics Canada 2008; Retrieved on May 13th, 2011. http://www.statcan.gc.ca

11. Butler-Jones D. The Chief Public Health Officer's Report on the State of Public Health In Canada. Ministry of Health 2008; Internet document retrieved on Mar 23, 2010. http://www.phac-aspc.gc.ca/ publicat/2008/cpho-aspc/pdf/cpho-report-eng.pdf

12. Butler-Jones D. The Chief Public Health Officer's Report on the State of Public Health in Canada. Ministry of Health 2011; Internet document retrieved on Nov 10, 2011. http://www.phac-aspc.gc.ca/ cphorsphc-respcacsp/2011/pdf/cpho-resp-2011-eng.pdf

13. Reynoso J, Susabda A, Cepeda-Benito A. Gender differences in smoking cessation. J Psychopathol Behav 2005;27:227-34.

14. Hiscock R, Bauld L, Amos A, et al. Socioeconomic status and smoking: a review. Ann N Y Acad Sci 2011;1248:107-23.

15. Koning $P$, Webbink $D$, Martin NG. The effect of education on smoking behaviour: evidence from smoking durations of a sample of twins. 2010. Internet document retrieved on Nov 10, 2011. http://ftp. iza.org/dp4796.pdf

16. Luijendijk HJ, Stricker BH, Wieberdink RG, et al. Transient ischemic attack and incident depression. Stroke 2011;42:1857-61.

17. Sibon I, Lasalle-Legadec S, Renou P, et al. Evolution of depression symptoms following stroke: a prospective study using computerized ambulatory monitoring. Cerebrovasc Dis 2012;33:280-5.

18. White CL, McClure LA, Wallace PM, et al. The correlates and course of depression in patients with lacunar stroke: results from the secondary prevention of small subcortical strokes (SPS3) study. Cerebrovasc Dis 2011;32:354-60.

19. Jatoi NA, Jerrard-Dunne P, Feely J, et al. Impact of smoking and smoking cessation on arterial stiffness and aortic wave reflection in hypertension. Hypertension 2007;49:981.

20. Benowitz NL. Pharmacology of nicotine: addiction, smoking-induced disease, and therapeutics. Annu Rev Pharmcol 2009;49:57-71.

21. Burn J, Dennis M, Bamford J, et al. Long-term risk of recurrent stroke after a first-ever stroke. The Oxfordshire Community Stroke Project. Stroke 1994;25:333-7.

22. Kamouchi M, Kumagai N, Okada $\mathrm{Y}$, et al. Risk score for predicting recurrence in patients with ischemic stroke: the Fokuoka stroke risk score for Japanese. Cerebrovasc Dis 2012;34:351-7.

23. Kawachi I, Colditz GA, Stampfer MJ, et al. Smoking cessation and time course of decreased risks of coronary heart disease in middle aged women. Arch Int Med 1994;154:169-175.

24. Xu G, Liu X, Wu W, et al. Recurrence after ischemic stroke in Chinese patients: impact of uncontrolled modifiable risk factors. Cerebrovasc Dis 2007;23:117-20.

25. Edjoc $\mathrm{R}$. The association between household restrictions and smoking abstinence: does age matter? J Smok Cess 2011;6:74-8

26. Evans J, Chen $\mathrm{Y}$. The association between home and vehicle environmental tobacco smoke (ETS) and chronic bronchitis in a Canadian population: the Canadian Community Health Survey, 2005. Inhal toxicol 2007;21:244-9.

27. Shields M. Smoking bans: influence on smoking prevalence. Health Reports 2007;3:9-24.

28. Smoke Free Ontario Act. Legislation 2009. Internet document. Retrieved on May 29, 2009. http://www.mhp.gov.on.ca/english/ health/smoke_free/legislation.asp

29. Smoke Free Ōntario Act. Legislation 2009. Internet document. Retrieved on May 29, 2009. http://www.mhp.gov.on.ca/english/ health/smoke free/chart.asp

30. Smoke Free Ontario Act. Legislation 2009b. Internet document Retrieved on May 29, 2009. http://www.e-laws.gov.on.ca/html/regs/ english/elaws regs 060048 e.htm

31. Ontario Tobacco Research Unit. Toward a Smoke Free Ontario: progress and implications for future developments. 2009; Internet document accessed on June 23rd, 2012. http://www.otru.org/pdf/ 13mr/13mr_no3.pdf

32. Ontario Tobacco Research Unit: Tobacco Control Funding Commitments. 2011; Internet document accessed on June 23rd. http://www.otru.org/pdf/mr2011/funding2011.pdf

33. Pierce JP, Gilpin EA, Emery SL, et al. Has the Tobacco Control Program reduced smoking? JAMA 1998;280:893-9. 
34. Pierce JP, Evans N, Farkas AJ. Tobacco use in California: an evaluation of the tobacco control program, 1989-1993. La Jolla: University of California, San Diego, 1994.

35. Shelley D, Yerneni R, Hung D, et al. The relative effect of household and workplace smoking restriction on health status among Chinese Americans living in New York City. J Urban Health 2007;84:360-71.

36. Fiore MC, Jaen CR, Baker TB, et al. Treating tobacco use and dependence: 2008 update. Rockville, MD: US Department of Health and Human Services. Public Health Service, 2008.

37. Eisenberg MJ, Filion KB, Yavin D, et al. Pharmacotherapies for smoking cessation: a meta-analysis of randomized controlled trials. CMAJ 2008;179:135-44.
38. Young JM, Ward JE. Implementing guidelines for smoking cessation advice in Australian general practice: opinions, current practices, readiness to change and perceived barriers. Fam Pract 2001;18:14-20.

39. Shaohua H, McAlister AL, Meshack AF, et al. Physician's views and practices of smoking cessation. Tex Med 2003; 99:57-63.

40. Holbrook AL, Green MC, Krosnick JA. Telephone versus face-to-face interviewing of national probability samples with long questionnaires: comparisons of respondent satisfaction and social desirability response bias. Public Opin Quart 2003; 67:79-125. 